\title{
Evaluation of psychological stress in scientific researchers during the 2019-2020 COVID-19 outbreak in China
}

\author{
Xueyan Zhang ${ }^{\text {Equal first author, 1,2 }}$, Xinyu Li ${ }^{\text {Equal first author, 1,2 }}$, Zhenxin Liao ${ }^{3}$, Mingyi Zhao ${ }^{\text {Corresp., } 4}$, Quan Zhuang ${ }^{\text {Corresp. } 1,5}$ \\ ${ }^{1}$ Transplantation Center, The 3rd Xiangya Hospital of Central South University, Changsha, Hunan, China \\ 2 Xiangya School of Medicine of Central South University, Changsha, Hunan, China \\ 3 Xiangya School of Public Health of Central South University, Changsha, Hunan, China \\ 4 Department of Pediatrics, The 3rd Xiangya Hospital of Central South University, Changsha, Hunan, China \\ 5 Research Center of National Health Ministry on Transplantation Medicine, Changsha, Hunan, China \\ Corresponding Authors: Mingyi Zhao, Quan Zhuang \\ Email address: 36163773@qq.com, zhuangquansteven@csu.edu.cn
}

Background: Beginning in December 2019, coronavirus disease 2019 (COVID-19) caused an outbreak of infectious pneumonia. The Chinese government introduced a series of grounding measures to prevent the spread of COVID-19. The living and working patterns of many scientific researchers also underwent significant changes during this period.

Methods: An opportunity sample $(n=251)$ was obtained in China using a questionnaire with 42 questions on scientific research progress and psychological stress during the COVID-19 epidemic.

Results: Of the 251 participants, $76.9 \%$ indicated that their research was affected by the COVID-19 outbreak, and participants who were affected by the outbreak had higher stress levels than those who were not affected. Participants who conducted COVID-19 research and indicated concern that they would fail to finish the research on time were more likely to indicate high levels of stress. Respondents indicated that extending deadlines (64.1\%), receiving support from superiors for research $(51.8 \%)$, and increasing benefits for researchers (51.0\%) would likely relieve outbreak-related stress.

Conclusion: The COVID-19 outbreak had a major impact on the experiments of researchers in the life sciences, especially in basic and clinical medicine. It has also caused high levels of psychological stress in these populations. Measures should be taken to relieve psychological pressure on basic medical researchers and students who will soon complete their degrees (e.g., Master's and PhD candidates in graduation years). 


\section{Evaluation of psychological stress in scientific researchers during the}

\section{9-2020 COVID-19 outbreak in China}

1 Xueyan Zhang ${ }^{1,2^{*}}$, Xinyu $\mathrm{Li}^{1,2^{*}}$, Zhenxin $\mathrm{Liao}^{3 *}$, Mingyi Zhao ${ }^{4}$, Quan Zhuang ${ }^{1,5}$

$2{ }^{1}$ Transplantation Center, The 3rd Xiangya Hospital of Central South University, Changsha,

3 Hunan, China.

$4{ }^{2}$ Xiangya School of Medicine of Central South University, Changsha, Hunan, China

$5{ }^{3}$ Xiangya School of Public Health of Central South University, Changsha, Hunan, China

$6{ }^{4}$ Department of Pediatrics, The 3rd Xiangya Hospital of Central South University, Changsha,

7 Hunan, China

$8{ }^{5}$ Research Center of National Health Ministry on Transplantation Medicine, Changsha, Hunan,

9 China

10

11 Corresponding Author:

12 Mingyi Zhao and Quan Zhuang

13138 Tongzipo Rd, Changsha, Hunan, 410013, China

14 Email address: 36163773@qq.com and zhuangquansteven@.csu.edu.cn

15 "These authors contributed equally to this article 


\section{Abstract}

17 Background: Beginning in December 2019, coronavirus disease 2019 (COVID-19) caused an outbreak of infectious pneumonia. The Chinese government introduced a series of grounding measures to prevent the spread of COVID-19. The living and working patterns of many scientific researchers also underwent significant changes during this period.

Methods: An opportunity sample $(n=251)$ was obtained in China using a questionnaire with 42 questions on scientific research progress and psychological stress during the COVID-19 epidemic.

Results: Of the 251 participants, $76.9 \%$ indicated that their research was affected by the COVID19 outbreak, and participants who were affected by the outbreak had higher stress levels than those who were not affected. Participants who conducted COVID-19 research and indicated concern that they would fail to finish the research on time were more likely to indicate high levels of stress.

27 Respondents indicated that extending deadlines (64.1\%), receiving support from superiors for research $(51.8 \%)$, and increasing benefits for researchers $(51.0 \%)$ would likely relieve outbreakrelated stress.

Conclusion: The COVID-19 outbreak had a major impact on the experiments of researchers in

31 the life sciences, especially in basic and clinical medicine. It has also caused high levels of psychological stress in these populations. Measures should be taken to relieve psychological pressure on basic medical researchers and students who will soon complete their degrees (e.g.,

34 Master's and $\mathrm{PhD}$ candidates in graduation years). 


\section{$37 \quad$ Introduction}

38

The outbreak of coronavirus disease 2019 (COVID-19), caused by severe acute respiratory syndrome coronavirus 2 (SARS-CoV-2), originated in Wuhan, China and quickly spread from human to human in December 2019 (Lai et al. 2020). On January 30, 2020, the World Health Organization declared the COVID-19 epidemic a public health emergency of international concern. As of February 23, 2020, China has confirmed 77,150 new coronavirus infections and 2,592 deaths (Pediatric Committee et al. 2020).(Martinez 2020). Because of the increasing number of confirmed cases and deaths, negative emotions continued to spread (Zhou 2020). Previous studies (Hull 2005; Wu et al. 2005a; Wu et al. 2005b) suggest we must examine the extent of psychological stress associated with the current epidemic and focus attention on those people most vulnerable to this psychological stress (Shigemura et al. 2020). Recent studies have focused on the psychological stress of the medical staff involved in epidemic prevention in China (Xiao et al. 2020). However, few studies have examined the impact of severe infectious disease outbreaks on the psychological state of researchers. The rise of stressors and strains in academic life has been widely reported (Kinman 2001). Heavy workload and time and resource constraints have been highlighted as major work stressors in researchers. The work-home imbalance and role conflict and overload also have potential impact on academic stress level (Gmelch et al. 1984; Kinman 2008; Tytherleigh et al. 2005). At the same time, stress from dissatisfaction with pay and benefits has been reported (Tytherleigh et al. 2005). Management and leadership styles, a pressured higher education climate, and unhealthy competition also cause harmful stress (Wellcome 2020).

To avoid further transmission of COVID-19, many industries were forced to shut down temporarily, and scientific and social research and education activities were paused in China (ScienceMag.org 2020b). Furthermore, animal centers and practical labs were closed, and many 
60 scientific and social congresses and symposiums were cancelled, leaving postgraduates and 61 scientific workers confined to their homes (ScienceMag.org 2020a). Therefore, many researchers'

62 experimental progress was hindered (e.g., due to loss of samples and funds) (ScienceMag.org 63 2020a; Tencent 2020a; Tencent 2020b), which undoubtedly increased the psychological stress on 64 academic and research staff. In addition, the stagnation of science education activities may cause 65 an increase in students' graduation pressure, and even the delay of graduation (Tencent 2020a).

In the current research, we propose the following hypotheses: (1) the COVID-19 outbreak

67 aggravated psychological stress in researchers; (2) the stress levels and stressors in diverse 68 populations would be different; (3) the demands for reducing stress in diverse populations would 69 be different. We included 42 related questions in a questionnaire to test the above hypotheses. 70 Respondents were categorized by research field, research degree, and affiliation, etc.

71 Materials \& Methods

72 Study participants

73 A questionnaire was distributed to researchers in China to recruit an opportunity sample, 74 and all respondents were asked to answer each question on their own. The targets of the 75 questionnaire were identified as "scientific researchers", which requires the respondents to be 76 involved in at least one research project in past 12 months. Questionnaires were distributed to 77 research institution staff, university researchers and students participating in the research. They 78 were all researchers with a confirmed scientific experience or people the authors had collaborated 79 with before. Some respondents passed on the questionnaire to other qualified people to fill in. A 80 total of 251 questionnaires was received after screening. As the investigators are scientific 81 researchers, they have a high level of education and are familiar with the questions. In addition, 82 the respondents' answers showed a high degree of consistency. Among all the respondents, 193 
83 chose "At a standstill" or "still in progress but slower than before" due to the epidemic situation 84 (question 37), while the same 193 respondents filled in the corresponding reasons and 85 psychological states (question 38 and 39), which was consistent in the filling. All participants 86 provided written informed consent, and subjects were anonymous. It is not required by our 87 institution to obtain ethical approval for a survey with a nonclinical sample and anonymised data,

88 but we did obtain retrospective approval for the study protocol from the institutional review board 89 (Ethics Committee) of the 3rd Xiangya Hospital, Central South University (20005-IRB).

\section{Questionnaire}

91 We included 42 related questions in the questionnaire to acquire a comprehensive understanding of the progress of research projects and the current psychological stress level of researchers. The survey consisted of 24 questions assessing the subject's psychological stress (i.e., stress scale). The questionnaire incorporated modified questions from the stress response questionnaire (SRQ) and the Pittsburgh sleep quality index scale (PSQI) (Pilz et al. 2018) and considered the current COVID-19 epidemic (i.e., emotional state, somatic responses, sleep quality and behavior). The stress scale consisted of five self-evaluation options: (1) not at all, (2) occasionally, (3) sometimes, (4) often, and (5) always. A score of 5 represented the highest level 99 of stress.

We also assessed participants' research areas (e.g., whether they conduct research related to the novel coronavirus) and potential stagnation of research projects, including questions rated 102 to (1) delay in scientific research projects, (2) sample or funding losses due to the current epidemic, 103 and (3) disruption of academic exchange activities. At the conclusion of the questionnaire, subjects were invited to evaluate some recommendations and proposed solutions for potential changes to 105 scientific research in China, including extending deadlines for project completion, providing 
106 partial financial subsidies for scientific research losses, assigning professional personnel to guide

107 and support scientific research projects, and prioritizing the return of researchers to work (see

108 Supplement 1).

109 Statistical analysis

110 Questionnaire results were summarized from the imported Excel file and analyzed using

111 SPSS version 18.0 software (IBM Corp., Armonk, NY, USA). Quantitative variables were

112 expressed as an average with a standard deviation (SD). Qualitative variables were expressed as

113 numbers and percentages. Chi-squared $\left(\chi^{2}\right)$ tests and analysis of variance (ANOVA) tests were

114 used to compare psychological factors across social roles and age groups. A P value less than or 115 equal to 0.05 was considered statistically significant.

\section{Results}

117 Participant demographics

118 Participants included scholars in the fields of life science (e.g., medicine, biology), 119 engineering science (e.g., mechanical engineering, physiology, chemistry) and humanities and 120 social sciences (e.g., law, literature). The gender ratio of the respondents was approximately 1:1.

121 The average age of participants was $28.91 \pm 8.65$, most of whom were from colleges or university 122 affiliated hospitals (Table. 1). Participants consisted of seven groups of people: undergraduate 123 students, Master's degree candidates (non-graduation year), Master's degree candidates 124 (graduation year), $\mathrm{PhD}$ candidates (non-graduation year), $\mathrm{PhD}$ candidates (graduation year), basic 125 research staff (including postdoctoral), and clinical medical staff (including postdoctoral). Many 126 participants were undergraduates and clinical medical staff without advanced degrees, who 127 comprise the majority of researchers in China and are therefore the most vulnerable to research128 related psychological stress from infectious disease outbreaks. 
129

130

131

132

133

134

135

136

137

138

139

140

141

142

143

144

145

146

147

148

149

150

151

\section{Impact of epidemic-related scientific delays on stress levels}

Of the 251 researchers surveyed, the average score of the population's stress level was $46.99 \pm 20.84$ points (full mark: 120 points). The median score was 43 points, the lowest score 24 points, and the highest score 120 points (Table 2). Participants whose progress was affected by the outbreak had higher levels of stress than participants who were not affected by the outbreak. Participants who indicated that they were affected by the epidemic expressed higher stress in emotional states, somatic responses, and behavior than participants who indicated they were not affected by the epidemic (Table 3 ).

We identified 14 possible predictors of high stress in researchers during the COVID-19 outbreak and conducted the variables with means and SDs on stress levels. As a result of the outbreak, researchers who were required to change or reduce experimental projects indicated they were under more pressure than those who did not have to change or reduce their experimental project. In addition, researchers were affected by peer pressure that their colleagues have been reporting on new coronavirus-related research (Table 4). We did not report a separate analysis of correlation between research stress and influencing factors in different research disciplines, due to the limited sample size. The impact of "Original research programs need to be changed or cut" on stress levels and the impact of "Feeling great pressure on colleagues who conduct projects on COVID-19" on stress levels are additionally listed in table 5 and 6.

\section{Responses regarding recommendations to improve conditions for scientific researchers}

Nine proposed solutions were considered by researchers to possibly ease their stress (Fig 1).

The top recommendation was prolonging the graduation/project conclusion/the deadline of the application of the funds, with 161 of $251(64.14 \%)$ respondents regarding it effective. Receiving support from superiors $(51.79 \%)$ and improving the welfare of researchers $(51.00 \%)$ came next. Academic 
152 cooperation $(27.49 \%)$ and meetings (21.91\%) received lower levels of endorsement. These

153 demands varied statistically between clinical staff and basic medical researchers, as well as

154 between master's and doctoral students (Table 7 and Table 8).

155 COVID-19 affected research progress differently across research fields and seniority

156 As a result of the COVID-19 outbreak, $47.11 \%$ of researchers in the field of science

157 indicated their research programs were halted, and $32.00 \%$ of researchers indicated their programs,

158 while ongoing, were slower than before the epidemic began. However, the COVID-19 epidemic

159 has had relatively little impact on researchers in the field of humanities, with most social science

160 researchers indicating a slower pace of research (6 out of 12) or a lack of impact of COVID-19 on

161 their research (5 out of 12 ). It is worth noting that we classify such scholars as "in the field of

162 humanities and social sciences", in fact, their research projects are concerning, say, "The human

163 impact of the epidemic" and "cultural reasons for differences in national responses". These types

164 of researches are scientific, though they tend to focus more on humanities. Of the 77 professors

165 and lecturers surveyed, 43 (55.84\%) indicated that their experiment was at a standstill, while 8

$166(10.39 \%)$ indicated that their experiment was not affected. However, the responses of researchers

167 without professional titles varied, with $43.82 \%$ of researchers indicating stagnated experiments

168 and $23.11 \%$ indicating unaffected projects respectively (Table 9 and Table 10).

169 Discussion

170 There may be many subjective or objective factors preventing the achievement of

171 motivating factors like job achievement, income, respect, reputation, work pride, promotion

172 opportunities, etc. Hindered scientific research progress may lead to reduced salaries and

173 promotion opportunities and could delay job achievement. It might also discourage many

174 researchers who had family or other social responsibilities. The resulting stress might be 
175 internalized and cause adverse psychological consequences (Kinman 2008; Liu et al. 2019). The

176 results showed participants whose progress was affected by the outbreak had higher levels of

177 stress. This is consistent with the study that work interruption is a common source of stress for

178 researchers (Gmelch et al. 1984). We found that researchers who reported needing to change their

179 original research programs often faced more pressure. This indicated the change of work content

180 in a short time may be difficult for researchers to deal with (Kinman 2001). Participants who

181 indicated pessimism about halted or slowed research progress also had higher levels of stress than

182 participants who were optimistic. These data provide evidence that we should promote the

183 importance of psychological and mental health in researchers and provide intervention guidance

184 during times such as infectious disease outbreaks (Jiang et al. 2020). In addition, previous research

185 has described that most researchers faced unhealthy competition and high levels of competitive 186 pressure at work (Randall et al. 2019; Wellcome 2020). In our study, researchers whose colleagues

187 were conducting related research on COVID-19 showed increased stress levels. This suggested 188 that with the full efforts of researchers to study COIVD-19, the stress of scientific research 189 competition also intensified.

190 To help determine interventions to reduce researchers' stress, we asked researchers to 191 provide suggestions regarding how to respond to the demands. The top recommendation was 192 extending the deadline for experimental projects. This was because the delay of experimental 193 progress often affected original research plans, such as applying for funding and students' 194 graduation. The results showed that "receiving support from superiors" would also help to reduce 195 stress. In previous studies, many respondents reported that their workplace put overwhelming 196 expectations on them and that the superiors' blame led to an increase in staff dissatisfaction. In 197 contrast, "respect" and "caring for others" were considered positive leadership styles (Kobulnicky 
198 1997; Merrill 2015; Morsiani et al. 2017; Wellcome 2020). In addition, inadequate salary and slow

199 career advancement have been considered as stressors for researchers (Gmelch et al. 1984; Kinman

200 2001). This explains the requirement to improve the welfare of researchers.

201 Importantly, with graduation deadlines approaching, many students may have felt pressure

202 to complete their qualifications. The lack of science educational activities during the pandemic

203 could entail delay of graduation. Furthermore, perceived stress was correlated with academic level:

204 stress increased with a higher academic level (Fadhel \& Adawi 2020). Also, uncertainty around

205 doctoral students and post-doctoral researchers' careers may have made them more vulnerable to

206 publication stress (Frandsen et al. 2019). We found that students pursuing a PhD degree showed a

207 stronger willingness to prioritize the return of researchers to work than students pursuing a 208 master's degree.

209

Researchers in the life sciences and engineering indicated that their scientific research was

210 more severely hindered than those in the social sciences and other fields. Most life sciences and 211 engineering fields rely on experimental facilities to complete their research; the closure of those 212 facilities during the epidemic created a great obstacle for completing their research 213 (ScienceMag.org 2020a; Tencent 2020a; Tencent 2020b). In contrast, researchers in social 214 sciences and other fields could often still conduct research activities during the outbreak.

215 This study has several limitations. The sample size was too small to conduct the population-

216 level sample comparisons that we had anticipated. Further, because this study took place one 217 month after the outbreak began, psychological stress may not have occurred yet. Long-term 218 psychological impacts of infectious disease outbreaks on scientific researchers, such as PTSD, 219 should be investigated in future studies. Finally, we did not compare researcher stress between 
220 Hubei (the initial and severe outbreak location) and other regions because there were few 221 respondents from Hubei.

\section{Conclusions}

223

Research progress was hindered by the COVID-19 outbreak, especially for researchers in

224 the life sciences (e.g., basic medicine and clinical medicine). Researchers who were affected by 225 the outbreak indicated higher psychological stress levels, especially emotional states, somatic 226 responses, and behaviors. Our investigation suggests that the pressure placed on researchers during 227 an epidemic comes mainly from lack of experimental progress and competition among peers. 228 Additionally, clinical medicine researchers were also concerned that the value of their 229 experimental results would be reduced because of delays in progress. The majority of respondents 230 indicated that effective ways to relieve stress included extending deadlines, receiving research 231 support from superiors, and increasing benefits for researchers. The results of this investigation 232 suggest that in addition to focusing on restoring normal order of the laboratory after the novel 233 coronavirus pandemic, it is also important to improve the psychological state of researchers.

\section{Acknowledgements}

235 This study was supported by grants from the National Natural Science Foundation of China 236 (81700658 and 81970248), the Hunan Provincial Natural Science Foundation-Outstanding Youth 237 Foundation (2020JJ3058), and the Medjaden Academy \& Research Foundation for Young 238 Scientists (nCoV_MJA20200221). 


\section{References}

240 Fadhel SeB, and Adawi TRT. 2020. Perceived stress and coping strategies among university students. . European Journal of Research in Medical Sciences:8 (1), 19-25.

Frandsen TF, Jacobsen RH, Nicolaisen J, and Ousager J. 2019. Pressure to publish: a bibliometric study of PhD students (1993-2009). Information Research-an International Electronic Journal 24:12.

Gmelch WH, Lovrich NP, and Wilke PK. 1984. Sources of Stress in Academe: A National Perspective. Research in Higher Education 20:477-490.

Hull HF. 2005. SARS control and psychological effects of quarantine, Toronto, Canada. Emerg Infect Dis 11:354; author reply 354-355. 10.3201/eid1102.040760

Jiang X, Deng L, Zhu Y, Ji H, Tao L, Liu L, Yang D, and Ji W. 2020. Psychological crisis intervention during the outbreak period of new coronavirus pneumonia from experience in Shanghai. Psychiatry Res 286:112903. 10.1016/j.psychres.2020.112903

Kinman G. 2001. Pressure Points: A review of research on stressors and strains in UK academics. Educational Psychology 21:473-492. 10.1080/01443410120090849

Kinman G. 2008. Work stressors, health and sense of coherence in UK academic employees. Educational Psychology 28:823-835. 10.1080/01443410802366298

Kobulnicky PJ. 1997. Commitment in the workplace: Theory, research and application - by John P. Meyer, John P. and Natalie J. Allen. Thousand Oaks, CA: Sage, 1997. 150p. \$34.00 (cloth). ISBN 0-7619-0104-3. \$15.95(paper). ISBN 0-7619-0105-1. Journal of Academic Librarianship 24:175.

Lai CC, Shih TP, Ko WC, Tang HJ, and Hsueh PR. 2020. Severe acute respiratory syndrome coronavirus 2 (SARSCoV-2) and coronavirus disease-2019 (COVID-19): The epidemic and the challenges. Int J Antimicrob Agents:105924. 10.1016/j.ijantimicag.2020.105924

Liu Y, Zhang J, Hennessy DA, Zhao S, and Ji H. 2019. Psychological strains, depressive symptoms, and suicidal ideation among medical and non-medical staff in urban china. $J$ Affect Disord 245:22-27. 10.1016/j.jad.2018.10.111

Martinez MA. 2020. Compounds with therapeutic potential against novel respiratory 2019 coronavirus. Antimicrob Agents Chemother. 10.1128/aac.00399-20

Merrill KC. 2015. Leadership style and patient safety: implications for nurse managers. J Nurs Adm 45:319-324. 10.1097/nna.0000000000000207

Morsiani G, Bagnasco A, and Sasso L. 2017. How staff nurses perceive the impact of nurse managers' leadership style in terms of job satisfaction: a mixed method study. J Nurs Manag 25:119-128. 10.1111/jonm.12448

Pediatric Committee MAoCPL, Army, and Editorial Committee of Chinese Journal of Contemporary P. 2020. Emergency response plan for the neonatal intensive care unit during epidemic of 2019 novel coronavirus. Zhongguo dang dai er ke za zhi = Chinese journal of contemporary pediatrics 22:91-95.

Pilz LK, Keller LK, Lenssen D, and Roenneberg T. 2018. Time to rethink sleep quality: PSQI scores reflect sleep quality on workdays. Sleep 41. 10.1093/sleep/zsy029

Randall ET, Shapiro JB, Smith KR, Jervis KN, and Logan DE. 2019. Under Pressure to Perform: Impact of Academic Goal Orientation, School Motivational Climate, and School Engagement on Pain and Somatic Symptoms in Adolescents. Clin J Pain 35:967-974. 10.1097/ajp.0000000000000765

ScienceMag.org. 2020a. 'The disruption is enormous.' Coronavirus epidemic snarls science worldwide. Available at https://www.sciencemag.org/news/2020/02/disruption-enormous-coronavirus-epidemic-snarls-scienceworldwide.

ScienceMag.org. 2020b. Does closing schools slow the spread of coronavirus? Past outbreaks provide clues.

Shigemura J, Ursano RJ, Morganstein JC, Kurosawa M, and Benedek DM. 2020. Public responses to the novel 2019 coronavirus (2019-nCoV) in Japan: Mental health consequences and target populations. Psychiatry Clin Neurosci. 10.1111/pcn.12988

Tencent. 2020a. Laboratory in the epidemic: closed, delayed graduation, stagnant project ... Available at http://zhishifenzi.com/depth/depth/8426.html.

Tencent. 2020b. Scientific research work in many places has "stagnation". How much has the academic community been affected by the epidemic? . Available at https://xw.qq.com/cmsid/20200222A08EHD00.

Tytherleigh MY, Webb C, Cooper CL, and Ricketts C. 2005. Occupational stress in UK higher education institutions: a comparative study of all staff categories. Higher Education Research \& Development 24:41-61. $10.1080 / 0729436052000318569$

Wellcome. 2020. What researchers think about the culture they work in. Available at 
https://wellcome.ac.uk/reports/what-researchers-think-about-research-culture.

294 Wu KK, Chan SK, and Ma TM. 2005a. Posttraumatic stress after SARS. Emerg Infect Dis 11:1297-1300. 10.3201/eid1108.041083

Wu KK, Chan SK, and Ma TM. 2005b. Posttraumatic stress, anxiety, and depression in survivors of severe acute respiratory syndrome (SARS). J Trauma Stress 18:39-42. 10.1002/jts.20004

Xiao H, Zhang Y, Kong D, Li S, and Yang N. 2020. The Effects of Social Support on Sleep Quality of Medical Staff Treating Patients with Coronavirus Disease 2019 (COVID-19) in January and February 2020 in China. Med Sci Monit 26:e923549. 10.12659/msm.923549

Zhou X. 2020. Psychological crisis interventions in Sichuan Province during the 2019 novel coronavirus outbreak. 
Figure 1

Figure 1. Some appeals that the researches consider effective to relieve the pressure of affected experiment (251 participants in total).

Some appeals that the researches consider effective to relieve the pressure of affected experiment (251 participants in total).

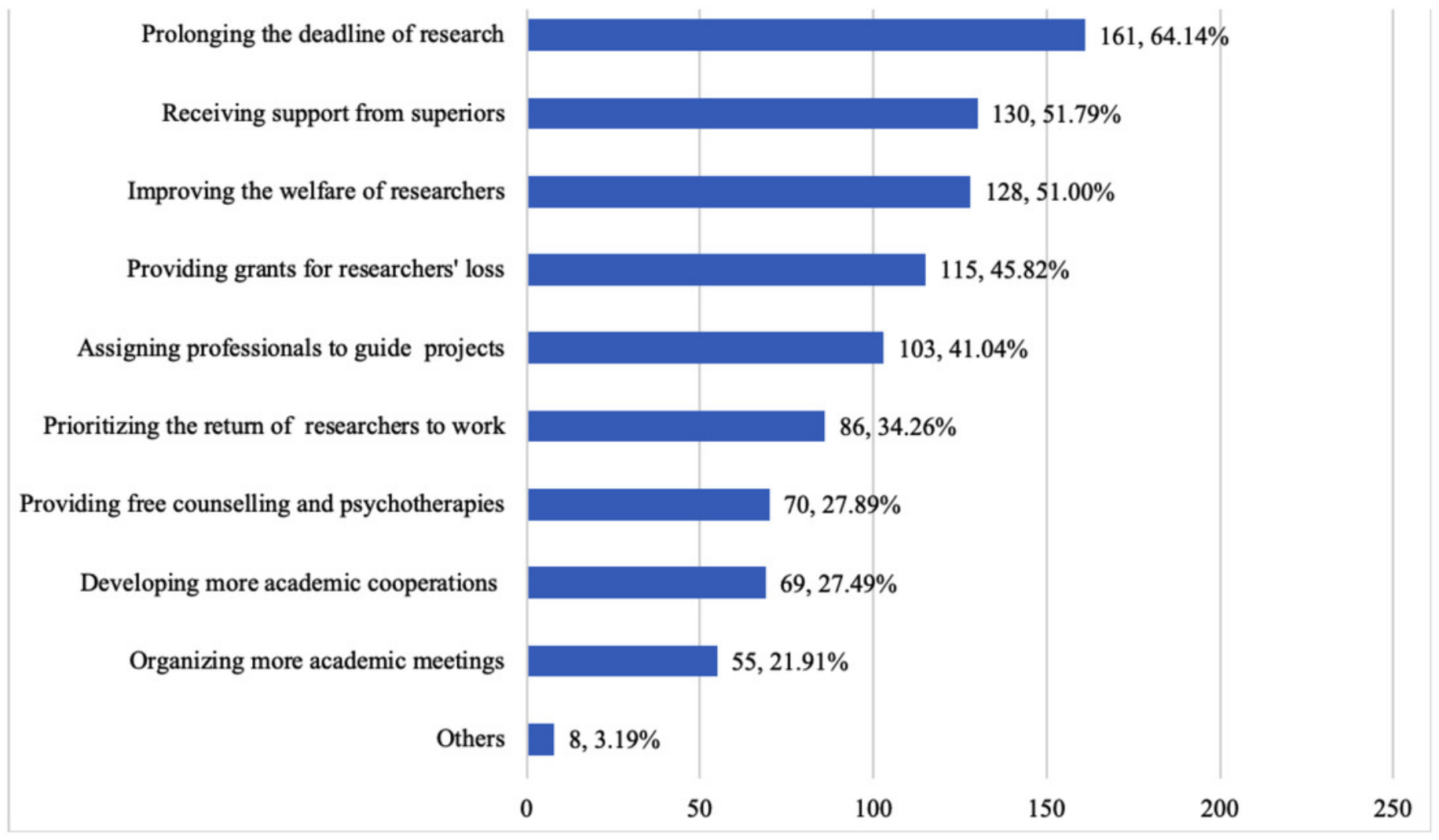




\section{Table 1 (on next page)}

Table 1. Demographic characteristics of respondents 
Table 1. Demographic characteristics of respondents

\begin{tabular}{|c|c|c|c|}
\hline \multicolumn{2}{|c|}{ Demographic characteristics } & \multirow{2}{*}{$\frac{\mathbf{N}}{104}$} & \multirow{2}{*}{$\frac{\%}{41.43}$} \\
\hline Condor & Male & & \\
\hline Genuer & Female & 147 & 58.57 \\
\hline \multirow{4}{*}{ Age } & $18-24$ & 109 & 43.43 \\
\hline & $25-39$ & 119 & 47.41 \\
\hline & $40-59$ & 22 & 8.76 \\
\hline & $\geq 60$ & 1 & 0.4 \\
\hline \multirow{5}{*}{$\begin{array}{l}\text { Category of school or } \\
\quad \text { institution }\end{array}$} & Top universities & 177 & 70.52 \\
\hline & General college & 13 & 5.18 \\
\hline & $\begin{array}{l}\text { Independent research institutes (including } \\
\text { research institutes) }\end{array}$ & 4 & 1.59 \\
\hline & University affiliated hospital & 55 & 21.91 \\
\hline & Non-university affiliated hospital & 2 & 0.8 \\
\hline \multirow{7}{*}{ Education background } & Undergraduates & 79 & 31.47 \\
\hline & Master candidate (non-graduate) & 28 & 11.16 \\
\hline & Master candidate (graduation grade) & 9 & 3.59 \\
\hline & PhD candidate (non-graduate year) & 23 & 9.16 \\
\hline & PhD candidate (graduation year) & 20 & 7.97 \\
\hline & Basic research staff (including postdoctoral) & 31 & 12.35 \\
\hline & $\begin{array}{l}\text { Clinical medical staff (including } \\
\text { postdoctoral) }\end{array}$ & 61 & 24.3 \\
\hline \multirow{4}{*}{ Title of technical post } & Professor (researcher, chief physician) & 11 & 4.38 \\
\hline & $\begin{array}{l}\text { Associate professor (associate researcher, } \\
\text { associate chief physician) }\end{array}$ & 22 & 8.76 \\
\hline & $\begin{array}{l}\text { Lecturer (assistant researcher, attending } \\
\text { physician) }\end{array}$ & 44 & 17.53 \\
\hline & None & 174 & 69.32 \\
\hline & Total & 251 & 100 \\
\hline
\end{tabular}

2 
Table 2 (on next page)

Table 2. Scores and statistical analysis of researchers' stress levels 
Table 2. Scores and statistical analysis of researchers' stress levels

\begin{tabular}{cccccc}
\hline \multirow{2}{*}{ Question number } & Dimensions & \multicolumn{3}{c}{$\mathrm{n}=251$} \\
\cline { 3 - 6 } & & Min & Max & Means \pm SDs & Median \\
\hline $13-20$ & Emotional state & 8 & 40 & $15.85 \pm 7.93$ & 14 \\
$21-25$ & Somatic responses & 5 & 25 & $10.18 \pm 5.05$ & 9 \\
$26-29$ & Sleep quality & 4 & 20 & $8.24 \pm 4.08$ & 7 \\
$30-36$ & Behavior & 7 & 35 & $12.73 \pm 5.50$ & 11 \\
& Total scores & 24 & 120 & $46.99 \pm 20.84$ & 43 \\
\hline
\end{tabular}

2 “ \pm " represents standard deviation

3 


\section{Table 3(on next page)}

Table 3. Impact of the delay of project on researchers' stress levels 
1

\begin{tabular}{ccccccc}
\hline \multirow{2}{*}{ Question number } & Dimensions & \multicolumn{2}{c}{$\begin{array}{c}\text { Completion date of scientific research project } \\
\text { was delayed by coronavirus. }\end{array}$} & \multirow{2}{*}{ F } & $\mathrm{p}$ \\
\cline { 3 - 4 } & & \multicolumn{2}{c}{ Disagree(n=83) } & Agree $(\mathrm{n}=168)$ & & \\
\hline $13-20$ & $\begin{array}{c}\text { Emotional state } \\
\text { Somatic }\end{array}$ & $13.72 \pm 6.24$ & $16.90 \pm 8.47$ & & 9.194 & $0.003^{* *}$ \\
$21-25$ & $\begin{array}{c}\text { Sesponses } \\
26-29\end{array}$ & $9.16 \pm 4.21$ & $10.68 \pm 5.35$ & & 5.181 & $0.024^{*}$ \\
$30-36$ & Sleep quality & $7.59 \pm 3.47$ & $8.55 \pm 4.32$ & & 3.131 & 0.078 \\
& Behavior & $11.35 \pm 4.42$ & $13.41 \pm 5.86$ & 8.021 & $0.005^{* *}$ \\
\hline
\end{tabular}

Table 3. Impact of the delay of project on researchers' stress levels

Completion date of scientific research project

$* \mathrm{p}<0.05 * * \mathrm{p}<0.01$, " \pm " represents standard deviation 


\section{Table 4 (on next page)}

Table 4. All the variables with means and SDs on stress levels 
Table 4. All the variables with means and SDs on stress levels

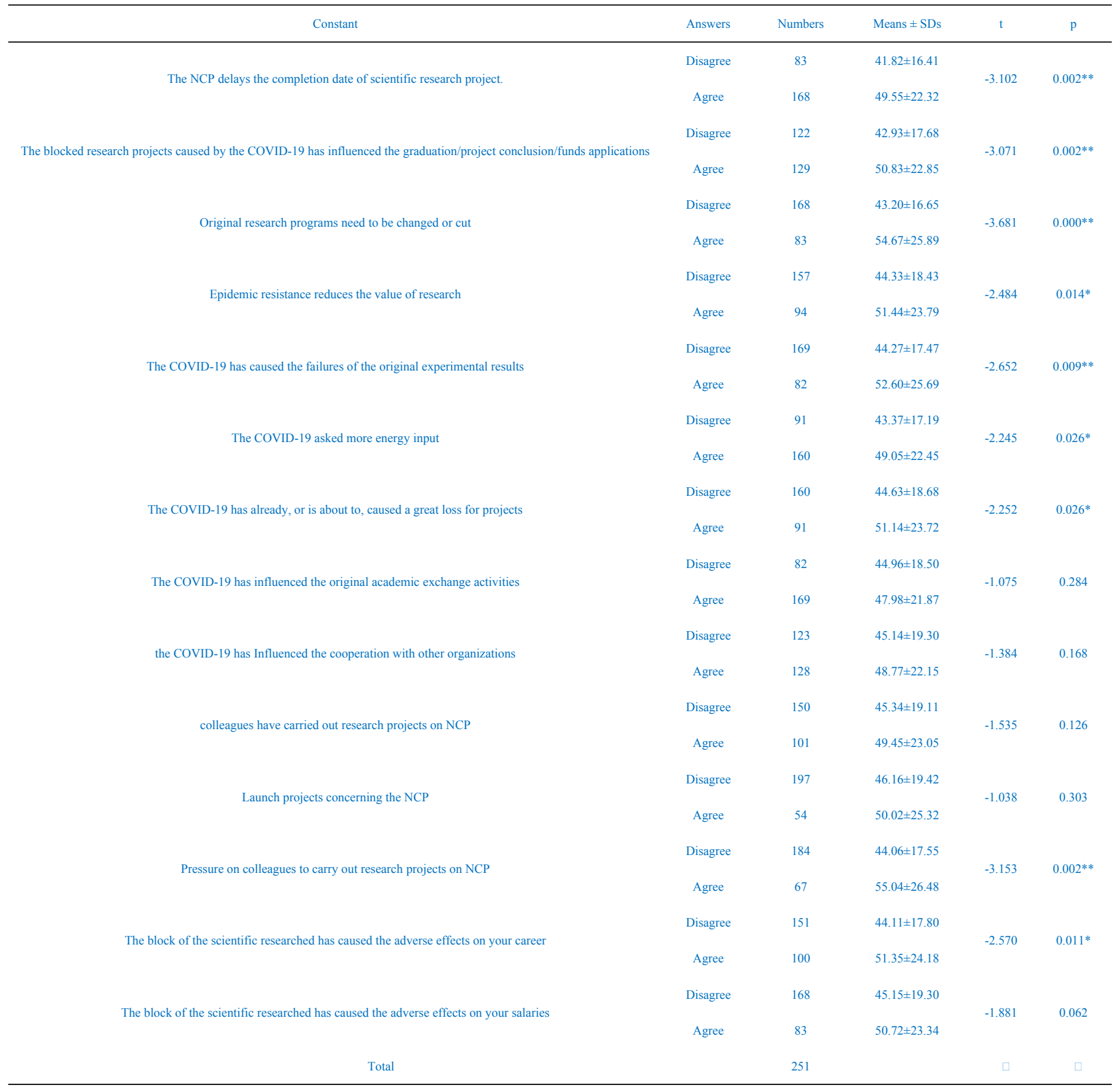

$* p<0.05 * * p<0.01$

2 


\section{Table 5 (on next page)}

Table 5. The impact of "Original research programs need to be changed or cut" on stress levels 
1 Table 5. The impact of "Original research programs need to be changed or cut" on stress levels

\begin{tabular}{|c|c|c|c|c|c|}
\hline \multirow{2}{*}{ Question number } & \multirow{2}{*}{ Dimensions } & \multicolumn{2}{|c|}{ Original research programs need to be changed or cut } & \multirow{2}{*}{$\mathrm{F} \square$} & \multirow{2}{*}{$\mathrm{p} \square$} \\
\hline & & disagree $(\mathrm{n}=168)$ & agree $(n=83)$ & & \\
\hline $13-20$ & emotional state & $14.25 \pm 6.31$ & $19.08 \pm 9.74$ & 22.391 & $0.000^{* *}$ \\
\hline $21-25$ & somatic responses & $9.32 \pm 4.14$ & $11.93 \pm 6.16$ & 15.775 & $0.000^{* *}$ \\
\hline $26-29$ & sleep quality & $7.80 \pm 3.51$ & $9.12 \pm 4.94$ & 5.971 & $0.015 *$ \\
\hline $30-36$ & behavior & $11.83 \pm 4.62$ & $14.54 \pm 6.61$ & 14.184 & $0.000^{* *}$ \\
\hline \multicolumn{2}{|c|}{ Total scores } & $43.20 \pm 16.65$ & $54.67 \pm 25.89$ & 18.001 & $0.000^{* *}$ \\
\hline
\end{tabular}

$* \mathrm{p}<0.05 * * \mathrm{p}<0.01$

2 
Table 6(on next page)

Table 6. The impact of "Feeling great pressure on colleagues who conduct projects on COVID-19" on stress levels 
1 Table 6. The impact of "Feeling great pressure on colleagues who conduct projects on COVID-19" on stress 2 levels

\begin{tabular}{ccccccc}
\hline \multirow{2}{*}{ Question number } & Dimensions & \multicolumn{2}{c}{ Feeling great pressure on colleagues who conduct projects on COVID-19 } & & $\mathrm{F} \square$ & $\mathrm{p} \square$ \\
\cline { 3 - 5 } & & disagree(n=168) & agree(n=83) & $18.73 \pm 9.89$ & 12.628 & $0.000^{* *}$ \\
\hline $13-20$ & emotional state & $14.80 \pm 6.82$ & $11.87 \pm 6.38$ & 10.605 & $0.001^{* *}$ \\
$21-25$ & somatic responses & $9.57 \pm 4.32$ & $9.49 \pm 5.21$ & 8.982 & $0.003^{* *}$ \\
$26-29$ & sleep quality & $7.78 \pm 3.48$ & $14.96 \pm 6.75$ & 15.861 & $0.000^{* *}$ \\
$30-36$ & behavior & $11.92 \pm 4.74$ & $55.04 \pm 26.48$ & 14.378 & $0.000^{* *}$ \\
\hline
\end{tabular}

$* \mathrm{p}<0.05 * * \mathrm{p}<0.01$

3 
Table 7 (on next page)

Table 7. A comparison of recommendations endorsed by basic medical researchers and clinical medical staff 
1 Table 7. A comparison of recommendations endorsed by basic medical researchers and clinical medical

2 staff

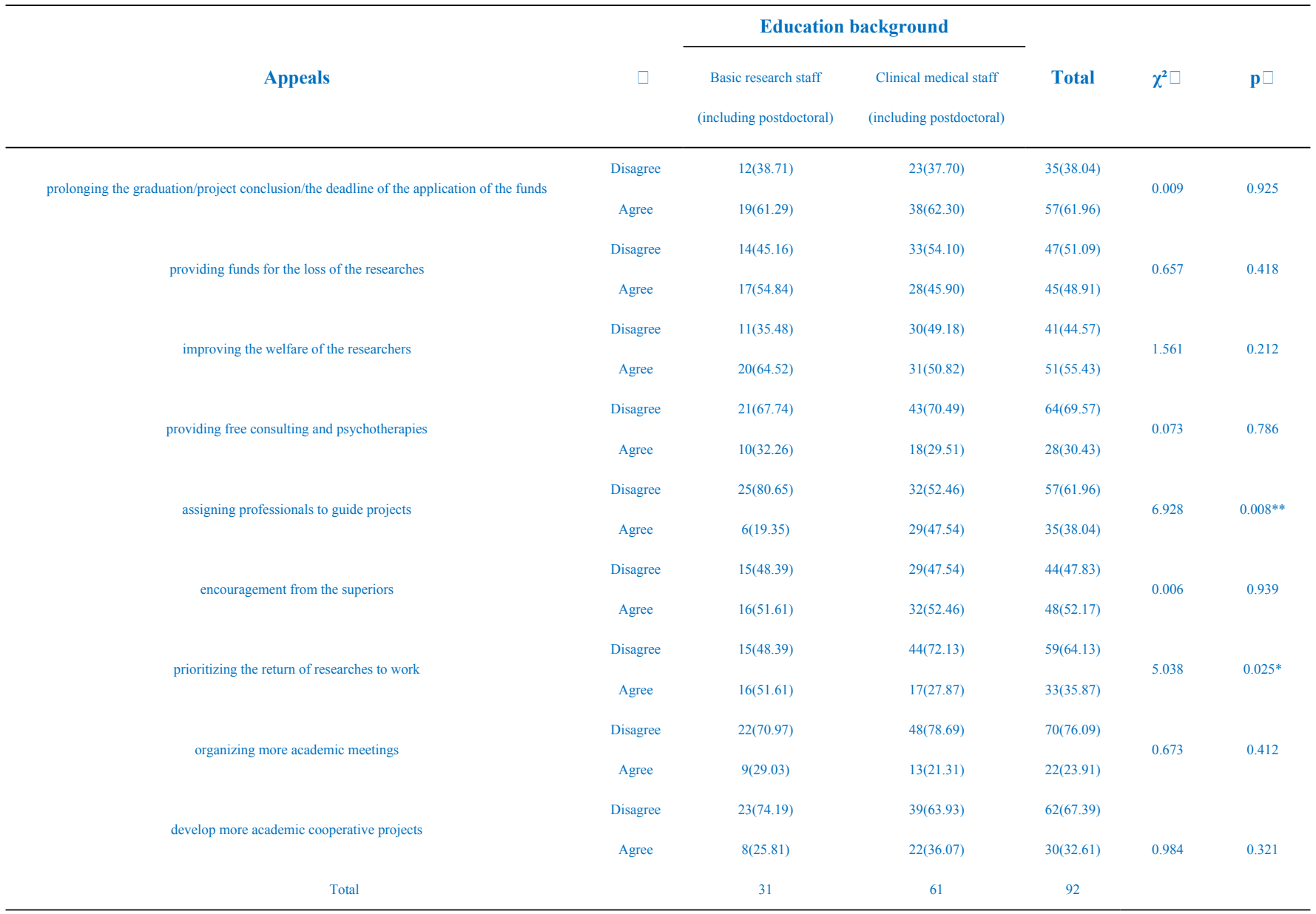

$* \mathrm{p}<0.05 * * \mathrm{p}<0.01$

3

4 


\section{Table 8(on next page)}

Table 8. A comparison of recommendations endorsed by masters and PhD students 


\begin{tabular}{|c|c|c|c|c|c|c|}
\hline \multirow{2}{*}{ Appeals } & \multirow{2}{*}{$\square$} & \multicolumn{2}{|c|}{ Education background } & \multirow{2}{*}{ Total } & \multirow{2}{*}{$\chi^{2} \square$} & \multirow{2}{*}{$\mathbf{p} \square$} \\
\hline & & Master & $\mathrm{PhD}$ & & & \\
\hline \multirow{3}{*}{ Prolonging the graduation or the expected finish time of the experiment } & Disagree & $14(37.84)$ & $17(39.53)$ & $31(38.75)$ & \multirow{3}{*}{0.024} & \multirow{3}{*}{0.877} \\
\hline & & & & & & \\
\hline & Agree & $23(62.16)$ & $26(60.47)$ & $49(61.25)$ & & \\
\hline \multirow{3}{*}{ Providing supports for the loss of the researches } & Disagree & $19(51.35)$ & 23(53.49) & $42(52.50)$ & \multirow{3}{*}{0.036} & \multirow{3}{*}{0.849} \\
\hline & & & & & & \\
\hline & Agree & $18(48.65)$ & $20(46.51)$ & $38(47.50)$ & & \\
\hline \multirow{3}{*}{ Improving the welfare of the researchers } & Disagree & $18(48.65)$ & $15(34.88)$ & $33(41.25)$ & \multirow{3}{*}{1.555} & \multirow{3}{*}{0.212} \\
\hline & & & & & & \\
\hline & Agree & $19(51.35)$ & $28(65.12)$ & $47(58.75)$ & & \\
\hline \multirow{3}{*}{ Providing free counselling and psychotherapies } & Disagree & $27(72.97)$ & $31(72.09)$ & $58(72.50)$ & \multirow{3}{*}{0.008} & \multirow{3}{*}{0.93} \\
\hline & & & & & & \\
\hline & Agree & $10(27.03)$ & $12(27.91)$ & $22(27.50)$ & & \\
\hline \multirow{3}{*}{ Assigning professionals to guide projects } & Disagree & $21(56.76)$ & $18(41.86)$ & $39(48.75)$ & \multirow{3}{*}{1.766} & \multirow{3}{*}{0.184} \\
\hline & & & & & & \\
\hline & Agree & $16(43.24)$ & $25(58.14)$ & $41(51.25)$ & & \\
\hline \multirow{3}{*}{ Supports from the superiors } & Disagree & $14(37.84)$ & $20(46.51)$ & $34(42.50)$ & \multirow{3}{*}{0.612} & \multirow{3}{*}{0.434} \\
\hline & & & & & & \\
\hline & Agree & $23(62.16)$ & $23(53.49)$ & $46(57.50)$ & & \\
\hline \multirow{3}{*}{ Prioritizing the return of researchers to work } & Disagree & $29(78.38)$ & $21(48.84)$ & $50(62.50)$ & \multirow{3}{*}{7.405} & \multirow{3}{*}{$0.007^{* *}$} \\
\hline & & & & & & \\
\hline & Agree & $8(21.62)$ & $22(51.16)$ & $30(37.50)$ & & \\
\hline \multirow{3}{*}{ Organizing more academic meetings } & Disagree & $31(83.78)$ & $33(76.74)$ & $64(80.00)$ & \multirow{3}{*}{0.616} & \multirow{3}{*}{0.433} \\
\hline & & & & & & \\
\hline & Agree & $6(16.22)$ & $10(23.26)$ & $16(20.00)$ & & \\
\hline \multirow{3}{*}{ Develop more academic cooperative projects } & Disagree & $30(81.08)$ & $33(76.74)$ & $63(78.75)$ & & \\
\hline & & & & & 0.224 & 0.636 \\
\hline & Agree & $7(18.92)$ & $10(23.26)$ & $17(21.25)$ & & \\
\hline
\end{tabular}

${ }^{*} \mathrm{p}<0.05 * * \mathrm{p}<0.01$ 
Table 9 (on next page)

Table 9. Research progress in different fields affected by COVID-19 
Table 9. Research progress in different fields affected by COVID-19

\begin{tabular}{ccccccc}
\hline & & \multicolumn{2}{c}{ Research field (\%) } & Total & $\chi^{2}$ & p \\
\cline { 3 - 5 } & & Science & Humanities & & & \\
\hline $\begin{array}{c}\text { Scientific research } \\
\text { projects you } \\
\text { participated in } \\
\begin{array}{c}\text { during the COVID- } \\
19 \text { outbreak are }\end{array}\end{array}$ & $\begin{array}{c}\text { Still under way but at a } \\
\text { slower pace than before }\end{array}$ & $72(32.00)$ & $6(50.00)$ & $78(32.91)$ & 7.158 & $0.028^{*}$ \\
\hline & Completely unaffected & $47(20.89)$ & $5(41.67)$ & $52(21.94)$ & & \\
\hline
\end{tabular}

$2 * \mathrm{p}<0.05 * * \mathrm{p}<0.01$

3 
Table $\mathbf{1 0}$ (on next page)

Table 10. Research progress under the influence of COVID-19 by different title of the technical post 
Table.10. Research progress under the influence of COVID-19 by different title of the technical post 2

\begin{tabular}{|c|c|c|c|c|c|c|}
\hline \multirow[b]{2}{*}{$\square$} & \multirow[b]{2}{*}{$\square$} & \multicolumn{2}{|c|}{ Title of the technical post (\%) } & \multirow[b]{2}{*}{ Total } & \multirow[b]{2}{*}{$\chi^{2}$} & \multirow[b]{2}{*}{$\mathbf{p}$} \\
\hline & & $\begin{array}{c}\text { Lecturers and } \\
\text { Professors }\end{array}$ & None & & & \\
\hline \multirow{3}{*}{$\begin{array}{l}\text { Scientific research } \\
\text { projects you } \\
\text { participated in } \\
\text { during the COVID- } \\
19 \text { outbreak are }\end{array}$} & At a standstill & $43(55.84)$ & $67(38.51)$ & $110(43.82)$ & \multirow{4}{*}{11.453} & \multirow{4}{*}{$0.003 * *$} \\
\hline & $\begin{array}{l}\text { Still under way but at a } \\
\text { slower pace than before }\end{array}$ & $26(33.77)$ & $57(32.76)$ & $83(33.07)$ & & \\
\hline & Completely unaffected & $8(10.39)$ & $50(28.74)$ & $58(23.11)$ & & \\
\hline & Total & 77 & 174 & 251 & & \\
\hline
\end{tabular}

$* \mathrm{p}<0.05 * * \mathrm{p}<0.01$

4 